\title{
$\bullet$ IJCRR \\ Section: Healthcare \\ Hospital Hygiene in the Training Program of the Higher Institute of Nursing Professions and Techniques of Health
} ISI Impact Factor (2019-20): 1.628 IC Value (2019): 90.81 SJIF (2020) $=7.893$

(c) (i) (3)

Copyright@IJCRR

\section{Nadia Chamkal ${ }^{1,2^{*}}$, Lahcen Bandadi ${ }^{1,2}$, Khadija Ounine ${ }^{1}$}

\author{
'Laboratory of Biology and Health, Faculty of Science, 1 bn Tofail University, Kenitra, Morocco; ${ }^{2}$ Higher lnstitute of Nursing Professions and \\ Techniques of Health, Rabat, Morocco.
}

\section{ABSTRACT}

Introduction: The prevention of hospital infections remains an important part of nursing work. To promote infection control, several studies have highlighted the role of hospital hygiene in basic training.

Objective: This study aims to describe the aspects of hospital hygiene in the training program of the Higher Institute of Nursing Professions and Techniques of Health. Methods: Descriptive and analytical study was conducted to explore the hospital hygiene place in the basic curricula. All modules contained in the curricula of student nurses (five options), health technicians (six options) and midwife were analyzed. A grid designed for this purpose was used to identify themes linked to hospital hygiene discipline.

Results: The findings of this study revealed that the hospital hygiene learning was planned only as themes among different common and disciplinary modules. The most important was attributed to patient hygiene and sterilization as principal elements of safety care. While other themes such as hand hygiene, protective personal equipment, medical waste management rarely occur.

Conclusion: In all option programs, hospital hygiene themes are envisaged, but scattered in different modules. We propose a transversal hospital hygiene module in all option programs. This allows global learning and thus the integration of knowledge and the development of skills required.

Key Words: Hospital Hygiene, Prevention and Control infection, training program, Higher Institute of Nursing Professions and Techniques of Health

\section{INTRODUCTION}

Care Safety and quality is a primary objective of all health system. ${ }^{1}$ this objective can only be achieved by adopting good practices to prevent risks. The infection transmissions among patients, professionals and family constitute the major risk whatever the care services. To prevent and control these infections, hospital hygiene as a medical discipline constitutes a relevant intervention guaranteeing quality and healthcare safety. ${ }^{2}$ This discipline takes into account the clinical, microbiological and epidemiological infection aspects, care organizations, hospital equipment maintenance, environmental management and personnel protection. ${ }^{3}$

In the nursing field, the prevention of hospital infections remains an important part of nursing work. ${ }^{4,5}$ The hospital hygiene nursing includes the analysis, the organization, the provision of nursing care and the care evaluation. ${ }^{6}$ For this reason, the nursing students who will be the future nurses are in the needs of hospital hygiene knowledge. Thus, to promote infection control, several studies have highlighted the role of hospital hygiene in basic training to equip staff with the skills required in this area, ${ }^{7-10}$ because the educational background is one of the factors influencing compliance with good practices. ${ }^{11}$ Hence, imparting and inculcating knowledge on hospital waste management improved their practices in hospitals. ${ }^{12}$ in this line, training workshops on biomedical waste management has shown promising results in practising biomedical waste management. ${ }^{13}$ In the same, kelcivoka et al. reported that the lack of compliance with hand hygiene standards among students leads to poor compliance among health care professionals in practice. ${ }^{14} \mathrm{How}-$ ever, the results of the Ward et al study showed that clinical supervisors perceive gaps in nursing student's theoretical knowledge of infection prevention and control. They also noted the inability of students to appropriately apply infection control precautions in the clinical environment. ${ }^{15}$ Thus,

\section{Corresponding Author:}

Nadia Chamkal, Laboratory of Biology and Health, Faculty of Science, Ibn Tofail University, Kenitra, Morocco.

Email: nchamkal@yahoo.fr; nadia.chamkal@uit.ac.ma

ISSN: 2231-2196 (Print)

ISSN: 0975-5241 (Online)

Received: 14.10 .2020

Revised: 23.12 .2020

Accepted: 27.01 .2021

Published: 25.04 .2021 
special attention has been paid to the quality of teaching and learning in terms of hospital hygiene for nursing students so that they, as future professionals, can meet the requirements of infection control in healthcare facilities. ${ }^{10,16,17}$ One study has investigated the teacher's perception of the integration of hospital hygiene in the nursing training program. ${ }^{16}$ some authors have examined the satisfaction of nursing students regarding hospital hygiene teaching. ${ }^{18,19}$ While others have analyzed the content program to research the place according to hand hygiene only as hospital hygiene theme. ${ }^{14}$ However, there is a concern to study the importance given to all hospital hygiene themes in nursing student programs, which is the purpose of this study.

\section{MATERIALS AND METHODS}

To explore the hospital hygiene place in the training program a descriptive and analytical study was conducted. The study took place in an institute of nursing and technics health in Morocco. It offers training in various options as a speciality. Twelve option programs have been studied: Five nursing care option programs (polyvalent nurses, anaesthetist nurses, emergency nurses, neonatal nurse and psychiatric nurses), six technician health options programs (laboratory, radiology, nutrition, pharmacy, statistics and health and environment) and finally midwife option program. The modules, as enshrinement units, of the nursing, health technicians and midwife student program, were analyzed.

Data was collected using a grid designed for this purpose. It consists of two axes, the first aims to determine the option title, module title. The second allows identifying the learning objectives, hospital hygiene themes as well as teaching/ learning methods. The hospital hygiene themes were identified by reviewing the literature. They are as follows: nosocomial infections; hand washing; personnel hygiene (body and cloths), personnel protective equipment (gloves, aprons and/or gowns, mask and eye protection), accident with exposure to blood, vaccination; patient hygiene, prophylactic antibiotic, isolation, the screening for bacterial carriage; decontamination, disinfection and sterilization and environmental hygiene (water, air and food at the hospital, surfaces disinfection, medical waste and the linen management).

To conduct this study, authorization has been obtained from the Director of the Higher Institute of Nursing Professions and Technics Health has been obtained.

\section{RESULTS}

The analysis of the nursing care, midwife programs revealed a hospital hygiene teaching divergence (Table 1). Such as a chapter for the midwife and three nursing care options with detailed themes only for a single nursing care option: the nosocomial infections mechanisms, the surveillance and prevention organization of the nosocomial infections, the hospital waste typology and the management methods. Whereas, in the others option programs, the teaching of hospital hygiene is mentioned only as fragmented themes in different modules.

The theme of personal hygiene (body and the clothing), is mentioned in midwife and three nursing care options curricula. Nevertheless, the personal protective equipment has not been described. It is noted the presence of some elements refer to risks, accidents at work and occupational diseases have also been described in the two nursing care options program. However, the vaccination and accident with exposure to blood themes do not appear in the curricula.

The results highlighted the priority addressed to the patient preparation, comfort and hygiene theme. It's an integral part of all nursing care and midwife option programs. However, the isolation techniques, the screening for bacterial carriage and the antibiotic prophylactic use are not registered. It is noticed that in the midwife and all nursing care options program, the material treatment and sterilization theme is included in both theoretical and practical modules. The content theme is only detailed for one option, which identified the concepts (disinfectant, pre- disinfection, and sterilization, the stages of the sterilization process and the control tools). Also, the teaching of this theme is reinforced through clinical teaching. Which, allow the student to contextualize, and decontextualize the knowledge acquired in the academic environment. This module is planned for the first year in all nursing care and midwife program before clinical placement.

The results show various elements addressed to the knowledge of environmental hygiene theme in nursing care programs, such as collective hygiene, control diseases vectors, waste sorting and treatment, pollution control and professional environment hygiene. Whereas, medical waste management has appeared in one nursing care option of nursing car and midwife programs. However, the others aspects of the environmental hygiene theme (air and water at hospital, surface disinfection, linen management) are not detected in all programs.

Regarding the teaching of food hygiene, it is planned for the midwife and almost all the nursing care options as part of a nutrition common module.

Table 2 illustrates hospital hygiene Themes in health technician programs. It shows that sterilization, food hygiene, occupational risks are the most occur themes targeted. For example, the sterilization theme is provided as part of a nursing care module for one option or integrated with disciplinary modules for the other options. On the other hand, the professional risks, environmental risks and accident preven- 
tion themes are included in a module shared by all health technician option programs focusing on quality, safety and risk management.

Other themes are only mentioned for one or two options such as the infectious risks, the care risks, personal protective equipment, hand washing, surgical hand disinfection and medical waste management. Finally, the results show that only one health technician option program offers a module titled hospital hygiene which contains the hospitals' hygiene measures, the prevention and the fight against nosocomial infections.

Concerning learning objectives, the results indicate that only some hospital hygiene themes are targeted by specific learning objectives, such as material sterilization in all nursing care, health technician and midwife options programs, personal hygiene theme (body and clothing) and prevention of nosocomial infections in one option program. On the other hand, a general objective relating to occupational health and environmental protection is expected to develop, either a chapter titled hospital hygiene, or themes relating to occupational risks and occupational accidents without be associated with healthcare settings. On the other hand, some objectives target safety and occupational risks, however, the care risks are translated by learning objective in one health technician option program. Also, this last comprehend the objectives targeted hand washing, food hygiene and medical waste.

Concerning the teaching didactics, it can not be evaluated for the hospital hygiene themes. Because the teaching methods are planned for all the content module. Thus, the most common educational methods are interactive presentation, preliminary lecture, collective lecture, group work, questioning and discussion. Other methods are also specified such as role-plays, case studies, demonstration, simulation, and audio-visual teaching.

\section{DISCUSSION}

The results show that the training programs provide hospital hygiene teaching as fragmented and isolated themes scattered in different modules. Consequently, the handwashing and rubbing theme is indicated only in one option program. In this sense, Kelc1'kova et al have noted the absence of the concept of hand washing or handwashing techniques in the nursing student program. ${ }^{14}$ The study conducted by Mahmood et al showed the importance of improving the current training programs targeting hand hygiene practices among nursing students. ${ }^{20}$ Also, the lack of knowledge is perceived by nursing students as a constraint to the observance of hand washing. ${ }^{14,21}$ This may hurt the knowledge and compliance among health care professionals. ${ }^{14}$
The personal hygiene theme is considered an important measure to prevent hospital infection. ${ }^{22}$ Nevertheless, the theme relating to body and clothing hygiene is absent in the health technician option programs. This might limit the knowledge among this category. In this order, one previous study revealed that $66.5 \%$ of medical students were dissatisfied with the hygiene course received during their training. And identified the insufficient knowledge of clothing hygiene among this population. ${ }^{23}$ In contrast, the personal protective equipment (PPE) theme is detected in one health technician option program. While it should be an essential component of nursing and midwifery programs in that these future professionals will be for the strong call to provide care that requires specific (PPE). In another context, the nurse students had qualified the education of (PPE) and hand hygiene as extremely superficial. ${ }^{24}$ One study had explained the poor knowledge among nurse students in term of PPE and Hand hygiene by insufficient infection control in training courses. ${ }^{18}$ Thus, reinforcing infection prevention education in the nursing program is important. ${ }^{19}$

This study revealed that all nursing care, midwife and health technicians programs studied include the themes related to professional risks and occupationally diseases. These results are consistent with those found by kelcivoka et al which highlighted the frequent presence in nursing curricula documents of concepts such as prevention of communicable diseases and nurses safety of disease transmissible. ${ }^{14}$ Nevertheless, the vaccination and accident with exposure to blood are not signalled. These themes constitute an important protective measure to take into consideration in education, ${ }^{7,17}$ such as exposure to blood as potentially influencing factor protect. ${ }^{7}$ and nursing students should have vaccination knowledge before they can practice. ${ }^{17}$

As regards the patient theme, his preparation and hygiene constitute the most important hospital hygiene measure present in all nursing care and midwife programs. However, the finding illustrates the absence of isolation and antibody therapy. Whereas this last is identified within the important purpose themes of education. ${ }^{16}$ Concerning the isolation, the previous finding showed that the nurse students acknowledge its importance in their education. ${ }^{19}$ Moreover, other authors suggest more training on infection control measures because their finding revealed the poor knowledge among nursing student about the isolation precaution of pulmonary tuberculosis infection. ${ }^{25}$

The most theme described in all programs studied is equipment sterilization. Furthermore, the learning objective linked to this theme is expressed by highlighting the safety and quality of care. Similarly, the previous finding revealed that the concepts of the disinfection process are detected frequently in the nursing program. ${ }^{14}$ As regards the environmental hygiene theme, the finding indicates that medical waste management is 
signalled only in three option programs. In this sense, several authors have reported that knowledge of medical waste management among nursing students is poor. ${ }^{12,26}$ Therefore, the nursing curriculum should give proper importance to medical waste management. ${ }^{26} \mathrm{Also}$, it is identified as an important purpose of education. ${ }^{16}$ However, this study has noted the absence of water, air and food at the hospital, surfaces disinfection, and linen management in all programs studied. While the immediate environment can cause wound contamination either from ambient air or contaminated surfaces. ${ }^{27}$ Also, contaminated surfaces contribute to the infection transmission risk and healthcare-associated infections. ${ }^{28-30}$

The single module titled hospital hygiene is included in one option of health technician programs as a Hygiene specialist. This module should be integrated into all nursing care, midwife and others health technician option programs. In fact that, it's important to standardize the course content of hospital hygiene. ${ }^{16}$ In other contexts, the important place is given to Hospital hygiene in the nursing student training program through the presence of modules directly related to this discipline. ${ }^{23,31}$ Also, the Health Technician programs incorporate a module concerning the quality approach. Which should be integrated into others nursing care and midwife programs, because the use of different tools such as protocols, procedures, evaluations, audit and traceability. ${ }^{3}$ allow continuous improvement of the care provided to patients and therefore guaranteed quality of care.

On the other hand, the analysis of the programs reveals the opportunity to acquire knowledge in nosocomial infections prevention through different modules planned in all programs studied such as microbiology, epidemiology, communicable and notifiable diseases. These modules were qualified as an important course of training of specialities related to Infection Control/ Hospital Hygiene. ${ }^{32}$ Thus, the thoughtful application of knowledge of microbiology allows preventing of infections, especially those emerging like SARS/COVID-19 by decontextualization, for example, the skill of adapting the practice of personnel protective equipment. ${ }^{17,33}$ Besides, the notifiable diseases require the vigilance of professionals and therefore contribute to nosocomial infections prevention. ${ }^{34}$

\section{CONCLUSION}

In all option programs, hospital hygiene themes are envisaged but scattered in different modules. One option program out of twelve, have a module titled hospital hygiene. We suggest harmonizing hospital hygiene learning in all option programs through a transversal module. This list should cover all hospital hygiene themes: nosocomial infections, epidemiology, microbiology, basic hygiene, vaccination and accident with exposure to blood, patient hygiene, isolation and Antibio-therapy, disinfection/ sterilization, environmental hygiene, and quality demarche. Therefore, global teachinglearning allows to development of skills in hospital hygiene. Besides, a course about care techniques and hygiene should be intended in midwife and nursing care programs.

Conflicts of Interest: No conflicts of interest

Funding: No funding source

Acknowledgements: I would like to thank the Director of ISPITSR

\section{Author's contribution}

\begin{tabular}{|l|l|l|}
\hline $\begin{array}{l}\text { Author } \\
\mathbf{N}^{\circ}\end{array}$ & Name author & Contribution \\
\hline 1 & Nadia Chamkal & $\begin{array}{l}\text { Concepts, Design, Literature } \\
\text { search, Data acquisition, Data } \\
\text { Analysis, Manuscript preparation, } \\
\text { Manuscript editing, Manuscript } \\
\text { review. }\end{array}$ \\
\hline 2 & Lahcen Bandadi & $\begin{array}{l}\text { Concepts, Design, Literature } \\
\text { search, Data Analysis, Manuscript } \\
\text { editing, Manuscript review. }\end{array}$ \\
\hline 3 & Khadija Ounine & $\begin{array}{l}\text { Concepts, Design, Literature } \\
\text { search, Data Analysis, Manuscript } \\
\text { editing, Manuscript review. }\end{array}$ \\
\hline
\end{tabular}

\section{REFERENCES}

1. World Health Organization. Patient safety: a global health priority. 2019. https://www.who.int/patientsafety/en/

2. Brusaferro S, Arnoldo L, Finzi G. Hospital Hygiene and Infection Prevention and Control in Italy: state of the art and perspectives. Annali d'igiene 2018;30 (5):1-6.

3. Kammoun H, Arfaoui C, Hamza R, Attia annabi T, Bouzouia $\mathrm{N}$, Mrabet Tanazefti K, et al. Hygiène Hospitalière: Concepts, domaines et methodes. Vol. 1. 2008.

4. Ipek Coban G, Bilgin S. Development of the scale of hygiene behaviors for nursing students. BMC Med Res Methodol 2015;15(69):1-6.

5. Monegro AF, Regunath H. Hospital Acquired Infections. Treasure Island (FL): StatPearls Publishing; 2020. http://www.ncbi. nlm.nih.gov/books/NBK441857/

6. French Society of Hospital Hygiene. Nurse in advanced practice and infection prevention and control. 2019. https://sf2h.net/wpcontent/uploads/2019/05/IPA_PCI_SF2H_2019-VLdef.pdf

7. Lymer U-B, Richt B, Isaksson B. Blood exposure: factors promoting health care workers' compliance with guidelines in connection with risk. J Clin Nurs 2004 ;13(5):547-554.

8. Nobile M, Agodi A, Barchitta M. The effectiveness of educational interventions in university training on hospital hygiene: results of action research. annali di igiene medicina preventiva e di comunità 2018; 30 (5):111-120.

9. Santana FR, Fortuna CM, Monceau G. Health promotion and disease prevention in professional nursing education in Brazil and France. Revue Education, Santé, Sociétés 2017;3(2):11535 .

10. Ward DJ. The role of education in the prevention and control of infection: A review of the literature. Nurse Educ Today 2011;31(1):9-17. 
11. D’Alessandro D, Agodi A, Auxilia F, Brusaferro S, Calligaris L, Ferrante M, et al. Prevention of healthcare associated infections: Medical and nursing students' knowledge in Italy. Nurse Educ Today 2014;34(2):191-5.

12. Gayathri, N, Kumaravel K. Effectiveness of Structured Teaching programme on Knowledge of Hospital Waste Management among Senior Nursing Students "Let the Waste of the Sick Not Contaminate the Lives of Healthy." J Nurs Health Sci 2018;7(6):86-91.

13. Rathod D, Jadav J, Vaghela S. Evaluation of awareness programme on practices of biomedical waste management at Teaching Hospital, Ahmedabad. Int J Curr Res Rev 2012;04(19):159164.

14. Kelcíkova S, Skodova Z, Straka S. Effectiveness of Hand Hygiene Education in a Basic Nursing School Curricula. Public Health Nurs 2012;29(2):152-159.

15. Ward DJ. The infection control education needs of nursing students: An interview study with students and mentors. Nurse Educ Today 2011;31(8):819-24.

16. Nobile M, Agodi A, Barchitta M. The effectiveness of educational interventions in university training on hospital hygiene: results of action research. annali di igiene medicina preventiva e di comunità 2018;(5):111-20.

17. Chang SO, Kyeong-Yae Sohng, Kim K, Won J, Min-Jung Choi, Seung-Kyo Chaung. Exploring How to Conduct Infection Prevention and Control Education in Undergraduate Nursing Programs in Korea: Focus Group Interview Analysis. J Korean Acad Fundamen Nurs 2019;26(3):210-20.

18. Abdelaziz T, Dogham R, Elcockany N. Infection prevention and control curriculum in undergraduate nursing program: Internship nursing students' perspectives. J Nurs Educ Pract 2019;9(10):59-66.

19. Carter EJ, Mancino D, Hessels AJ, Kelly AM, Larson EL. Reported hours of infection education received positively associated with student nurses' ability to comply with infection prevention practices: Results from a nationwide survey. Nurse Educ Today 2017;53:19-25.

20. Mahmood S, Verma R, Khan M. Hand hygiene practices among nursing students: importance of improving current training programs. Int J Community Med Public Health 2015 ;466-71.

21. Barrett R, Randle J. Hand hygiene practices: nursing students' perceptions. J Clin Nurs 2008;17(14):1851-7.

22. Hutzschenreuter L, Hübner N-O, Dittmann K, Hassel A-V, Flessa S. Potential of innovations in hygiene management a managerial perspective. Antimicrob Resist Infect Control 2019;8(100):2-10.

23. Duroy E, Le Coutour X. Hospital hygiene and medical students. Med Infect Dis 2010;40(9):530-536.
24. Sousa Á, Matos MCB, Matos JGNF de, Sousa LRM, Moura MEB, Andrade D de. Prevention and control of infection in professional nursing training: a descriptive study. Braz J Nurs 2017;16(2):199-208.

25. Olorunfemi O, Oyewole OM, Oduyemi RO. Nursing students' knowledge and practice of infection control in Burns and Medical-Surgical Units at the University of Benin Teaching Hospital, Nigeria. J Nurs Midwifery Sci 2020 ;7(1):42-6.

26. Gururajan M, Thirumalraja D. Comparison of Knowledge and Attitude between Student Nurses and Nursing Staff on Biomedical Waste Management in Tertiary Care Research Hospital, Puducherry-A Cross Sectional Survey. Int J Innov Stud Sociol Humanit 2018;3(12):1-4.

27. Ridha H, Hayet K, Mahmoud D. Hospital Hygiene and CareAssociated Infection Control. 2011. http://sotugeres.org/ wp-content/uploads/2016/05/HYGIENE-HOSPITALIEREET-LUTTE-CONTRE-LES-INFECTIONS-ASSOCIEESAUX-SOINS-V2.pdf

28. Otter JA, Yezli S, Salkeld JAG, French GL. Evidence that contaminated surfaces contribute to the transmission of hospital pathogens and an overview of strategies to address contaminated surfaces in hospital settings. Am J Infect Control 2013;41(5):S6-11.

29. Paz V, Paniagua M, Santilla'n A, Alaniz M, D'Agostino L, Orellana $\mathrm{R}$, et al. Hospital environment hygiene nurse: a key player to reduce healthcare associated infections by multi-resistant organisms. Infect Prevent Practice 2019;2:1-3.

30. Provincial Infectious Disease Advisory Committee. Best Environmental Cleaning Practices for Infection Prevention and Control in all Health Care Settings 2018. https:/www.publichealthontario.ca/-/media/documents/B/2018/bp-environmentalcleaning.pdf?la $=\mathrm{fr}$

31. Marras J-M. The place of hospital hygiene in the new curriculum of the State Diploma of Nursing 2010. http://www.cpiasauvergnerhonealpes.fr/Newsletter/2010/45/0_programme_infirmier.pdf

32. Brusaferro S, Arnoldo L, Cattani G, Fabbro E, Cookson B, Gallagher R, et al. Harmonizing and supporting infection control training in Europe. J Hosp Infect 2015;89(4):351-356.

33. Cox JL, Simpson MD. Microbiology Education and Infection Control Competency: Offering a New Perspective. J Microbiol Biol Educ 2018;19(2):1-6.

34. Phaneuf M, Gadbois C . Nosocomial infections - Working together for safe and healthy clinical environments 2010. http:// www.infiressources.ca/infiressources/RessourcesFrame. aspx?lang $=\mathrm{fr}$ 